\title{
Experimental Evidence for the Existence of the Passive Antitumor Defense System Formed by the Synergistic Action of Certain Small Substances of the Circulatory System
}

\author{
Gyula Kulcsár \\ Department of Biochemistry and Medical Chemistry, Faculty of Medicine, University of Pécs, Pécs, \\ Hungary
}

\begin{abstract}
In AIDS, only a few types of tumors (mainly Kaposi's sarcoma and non-Hodgkin's lymphoma) increase in incidence despite global abnormalities in the immune system. In addition, the reason for the higher incidence of these tumors is not immunosuppression but other agents. This shows that the immune system has no absolute role in the prevention of tumors. Consequently, the fact that tumors do not develop in the majority of the population during their lifetime, indicates the existence of other defense system $(s)$. We demonstrated previously that a mixture of 16 substances (selected experimentally out of 89 compounds of the circulatory system using the synergistic tumor cell-killing effect as criteria) had a cytotoxic effect (inducing apoptosis) in vitro and in vivo on tumor cell lines, but not on normal cells in vitro or animals. In our hypothesis these substances (L-tryptophan, L-tyrosine, L-methionine, L(-)malate, L-ascorbate, L-arginine, L-phenylalanine, L-histidine, 2-deoxy-D-ribose, d-biotin, pyridoxine, adenine, riboflavin, $D(+)$-mannose, orotate, and hippurate) are the active agents of a passive antitumor defense system (PADS). On the basis of the results, a tablet and a cream were developed, and an infusion is in preclinical phase. In this study we demonstrate that the above-mentioned substances can kill tumor cells when the experimental protocols, concentrations, and cell numbers are chosen to be comparable to the physiological conditions that exist in the living system when these substances fight against arising cancer cells. The results of our experiments demonstrate that the PADS really works in the human body.
\end{abstract}

Key words: apoptosis, immune system in AIDS, passive antitumor defense system (PADS), human and murine cancer cell lines, in vitro and in vivo, cytotoxic effect, DNA fragmentation, gel electrophoresis

\section{INTRODUCTION}

It is well known that full-blown AIDS is associated with substantial loss of virtually all cellular

Address reprint requests to: Gyula Kulcsár, Department of Biochemistry and Medical Chemistry, Faculty of Medicine, University of Pécs; Szigeti út 12, H-7624 Pécs, Hungary; Tel.: +36-72-536000/1953; Fax: +36-72-53677

e-mail:Gyula.Kulcsar@aok.pte.hu and humoral immune responses. ${ }^{1-4}$ This is demonstrated by the rejection-free renal graft survival in a patient with AIDS, despite the significant and prolonged withdrawal of the usual immunosuppressive agents used in renal transplants. ${ }^{5} \mathrm{Be}-$ cause of the global defects of the known immune system in AIDS, the incidence of all tumors should increase in AIDS populations if the known immune system were the only mechanism to prevent the development of tumors. Contrary to ex- 
pectations, only the incidence of some types of tumors, mainly Kaposi's sarcoma (KS) and nonHodgkin's lymphoma (NHL), has increased significantly. ${ }^{6,7}$ Taking into consideration that (1) a significant, continuous fall was observed in the percentage of AIDS-related KS in European AIDS cases $(p \text {-trend }<0.0001)^{8}$; (2) large differences can be observed in tumor incidence between homosexual, and heterosexual, hemophilic, and injection-drug-user AIDS patients ${ }^{2,9}$; (3) cohort studies indicate that KS occurs at a relatively constant rate before immune suppression becomes profound (starting 1-2 years after HIV infection), and the incidence does not increase as the immune function declines ${ }^{10}$; and (4) an increase in the incidence of KS and NHL has not yet been described in children with AIDS, who have also been treated and then examined regularly over an extended period ${ }^{11}$; it can be stated that even in the case of the above-mentioned tumors the reason for the high incidence is not defects of the immune mechanism. This is supported by epidemiological observations showing that the increase of incidence is caused by other effects (viruses, Tat protein of HIV, etc.). ${ }^{12,13}$ In summation, the activity of the known immune system declines, but the incidence of tumors still does not increase in consequence.

We can exclude the short survival time of patients as the reason for that, because in clinical reports a variety of other malignancies in HIVinfected persons ${ }^{6,14}$ and in immunosuppressed organ allograft recipients ${ }^{2,15}$ have been noted, but their frequency is no higher than in the healthy population.

We can also exclude the fact that the majority of tumors are eliminated by the remaining part of the immune system, because it is unable to reject renal graft in AIDS patients ${ }^{5}$ and the low levels of immune reaction facilitate rather than inhibit tumor growth (enhancement). ${ }^{16-18}$

The explanation that natural killer cells and macrophages have a role in tumor prevention in the above cases is refuted by many publications. ${ }^{15,19}$ The impairment of natural-killer-mediated cytotoxicity by plasma of cancer patients is correlated to their nucleosome concentrations, because the nucleosomes released from dead cells may allow the tumor cells to escape naturalkiller-mediated lysis. ${ }^{20}$ It has been strongly suggested that tumor-associated macrophages may even promote tumor growth. ${ }^{21-23}$ The observations made in connection with AIDS, including the diminished cytotoxic capability and pool sizes of natural and lymphokine-activaded killer cells, the abnormal function of monocytes and macrophages, ${ }^{1-4}$ and the unchanged incidence of the majority of tumors despite these, supply the strongest evidence against the general tumor-preventive role of natural killer cells and macrophages in vivo.

The above findings strongly support that the known immune system has no significant role in the prevention of tumor development.

This conclusion is corroborated by many of other publications. For example, the tumors possess different active and passive mechanisms of immune escape, including Fas ligand expression by the tumor, immunosuppressive cytokines, inhibitory neuropeptides and so forth as active mechanisms, and inadequate expression of adhesion and costimulatory molecules (e.g., B-7) as passive mechanisms. ${ }^{24}$ The majority of clinically relevant tumors are not, or only weakly, immunogenic. 2,25

Despite the ineffectiveness of the known immune system detailed above, the majority of people do not die from tumors. There are two possible explanations for this contradiction. First, there is no defense against tumors - a tumor may develop from every cell arising, and only the rise of a cancer cell is a rare singular event. This assumption includes the high vitality of cancer cells under any condition. However, this contradicts the observation that the cell death rate is still high within non-necrotic tumor tissue, ${ }^{26}$ that $70 \%$ to $90 \%$ of newly produced tumor cells in humans die spontaneously by a mechanism that is as yet poorly understood, ${ }^{27}$ and that millions of tumor cells can be shed into the circulation every day from a rapidly growing tumor $1 \mathrm{~cm}$ in size, but only a very small percentage $(<0.01 \%)$ initiate metastatic colonies. ${ }^{28}$

The other possible explanation is that cancer cell formation is quite common, but that the majority of cells are not able to multiply to produce a tumor because they die shortly after they arise. The reasons for death may either be entirely random effects or the action of a systematic defense system. Were cell death an absolutely accidental event and were it to occur independently of any kind of defense mechanism, the simultaneous development of a number of primary tumors in organs should be a relatively frequent occurrence. However, the development of even double synchronous primary tumors is rather rare. ${ }^{29,30}$ Therefore, the fact that tumors do not develop in the majority of the population during their life- 
time, despite the ineffectiveness of the known immune system, can only be explained by assuming that the arising tumor cells are destroyed by the action of other systematic defense system or systems.

Obviously, the components of a general defense mechanism (a "surveillance") must be in the circulatory system. It is well known that different small substances of the circulatory system (amino acids, monosacharides, nucleobases, vitamins, membrane permeable intermediates of cell metabolism, etc.) can reach and enter both normal and tumor cells. Their uptake by normal cells is regulated, but there is abundant evidence that the uptake of the majority of these substances by tumor cells is increased, unregulated and proportional to their availability. ${ }^{31-35}$ A net flux of them occurs toward the tumor cells, and they may attain high levels relative to the levels in surrounding normal tissues. ${ }^{32,33}$ These observations are well known and widely accepted; what is more, some techniques of tumor detection (e.g., positron emission tomography) use this feature of cancer cells. ${ }^{35,36}$

According to our hypothesis, the above feature of tumor cells may be fatal for them because some of the mentioned substances may be toxic if their concentrations can reach high levels in the cells. We speculate that these substances destroy the arising tumor cells in the majority of the population during their lifetime, if the number of cells arisen is not too high (absence of strong carcinogenic effects) or the concentrations of the required substances are not too low (healthy subjects, balanced food intake). Otherwise, the number of tumor cells arising can exceed a critical value (critical cell number) at which the divisions of cells overcompensate the killing of cells by the mentioned substances, and if the cancer cells are not immunogenic it is most likely that a tumor develops. The killing of tumor cells by the given substances form the passive antitumor defense system (PADS).

There are many examples of substances or proteins that have more than one fundamentally different role in the living systems (e.g., glutamate: building block of proteins and important neurotransmitter; glycogen synthase kinase-3: an enzyme that regulates glycogen synthesis and a member of survival signaling pathway, etc.) The known function of the "killer" molecules of PADS is not protection of the organism but, according to our hypothesis, they have a protective role, as a second function, when tumor cells arise and exist. This dual role is very similar to the protective role of substances (e.g., fatty acids, porphyrins, lactic acid, etc.), which (besides their well known other functions) are bactericidal to certain pathogenic microorganisms. ${ }^{15}$ However, the tumor cells do not differ to such an extent from the normal cells, like the nonself pathogenic microorganisms. To the best of our knowledge, there is no absolute, qualitative difference between normal and tumor cells at all. This precludes the possibility that a single compound can destroy the tumor cells selectively; killing them needs the collective, simultaneous, synergistic effect of more than one cooperating substance.

We demonstrated previously ${ }^{37-40}$ that the mixture of 16 substances (L-tryptophan, L-tyrosine, L-methionine, L(-)malate, L-ascorbate, L-arginine, L-phenylalanine, L-histidine, 2-deoxy-D-ribose, d-biotin, pyridoxine, adenine, riboflavin, orotic acid, hippuric acid, and D(+)-mannose), selected experimentally on the basis of the above hypothesis out of 89 substances of the circulatory system, had a cytotoxic effect in vitro and in vivo on various tumor cell lines, but not on normal cells in vitro and animals. In the experiments, the mixture of the above substances was called the active mixture. It was also proved by different methods that active mixture induced apoptosis of tumor cells, but not normal cells. ${ }^{39,40}$ We collected from the scientific literature much experimental data, epidemiological, and clinical observations that support our hypothesis about PADS. The collection of these data and observations have been published. ${ }^{40,41}$

In this study, we investigate whether the existence and operation of PADS can be demonstrated experimentally. Therefore, in the experiments reported in this present paper, the experimental protocols, concentrations, and cell numbers were chosen to be comparable to the physiological conditions that probably exist when the above-mentioned substances, the supposed agents of PADS, fight against arising cancer cells.

\section{MATERIALS AND METHODS}

\section{Materials}

Adenine, L-arginine, L-phenylalanine, L-histidine, L-tryptophan, L-tyrosine, L-methionine, 2deoxy-D-ribose, L(-)malic acid, d-biotin, pyridoxine, riboflavin, L-ascorbic acid sodium salt, $\mathrm{D}(+)$-mannose, and sodium bicarbonate (all of them were cell culture tested biochemicals) were 
purchased from Sigma-Aldrich Co. (Budapest, Hungary). RPMI-1640, trypan blue, folic acid, hypoxanthine, D-pantothenic acid hemicalcium salt, orotic acid monosodium salt, hippuric acid sodium salt, and betaine were also purchased from Sigma-Aldrich Co. (Budapest, Hungary). Amino acid Kit (AS-30), nicotinamide, and thiamin hydrochloride were obtained from Serva Feinbiochemica GmbH \& Co. (Heidelberg, Germany), succinic acid disodium salt from FLUKA AG (Buchs, SG, Switzerland), and fetal calf serum from Sebak GmbH (Aidenbach, Germany). All other chemicals were of the purest grade available from Reanal Finechemical Co. (Budapest, Hungary).

\section{Mice}

Six (6)- to 8-week-old female BALB/c mice were obtained from Department of Immunology and Biotechnology, University of Pécs (Pécs, Hungary). All mice were housed in plastic cages, five mice per cage, and provided with food and water ad libitum.

\section{Tumor Cells and Culture}

The Sp2/0-Ag14 mouse myeloma cell line was kindly provided by Prof. Dr. Péter Németh. The K562 human erythroleukemia cell line was the kind gift of Prof. Dr. Júlia Szekeres. The Sp2/0Ag14 and K562 cells were cultured in RPMI 1640 medium containing L-glutamine $(2 \mathrm{mM})$, penicillin $(100 \mathrm{U} / \mathrm{mL})$, streptomycin $(100$ $\mu \mathrm{g} / \mathrm{mL})$, and $10 \%$ fetal calf serum. The cells were incubated in a humidified atmosphere of $5 \% \mathrm{CO}_{2}$ at $37^{\circ} \mathrm{C}$. All cell lines were free of Mycoplasma.

\section{Cytotoxicity Assay}

The effect of mixtures was assessed by adding the components dissolved in the applied medium in the indicated concentrations to cultures in 96well or 24-well microplates or in Petri dishes. The logarithmically growing Sp2/0-Ag14 and K562 cells were harvested from the medium and resuspended to a final concentration, depending on the kind of experiment, in $250 \mu \mathrm{L}$ or $1 \mathrm{~mL}$ or 25 $\mathrm{mL}$ appropriate medium containing the tested mixture. The compositions of active mixtures and control mixtures are given in the figure legends. At the end of our experiments the number of viable Sp2/0-Ag14 and K562 cells was counted microscopically with trypan blue dye exclusion method, or the cell death was detected visually by invert microscope, or the cultures were photographed directly from the culture plates.

\section{DNA Gel Electrophoresis}

DNA fragmentation was monitored by gel electrophoresis as described previously. ${ }^{42}$ Briefly, the untreated, control mixture, or active mixture treated K562 cells, were collected by centrifugation, washed in buffer $(140 \mathrm{mM} \mathrm{NaCl}, 3 \mathrm{mM}$ $\mathrm{KCl}, 8 \mathrm{mM} \mathrm{Na} \mathrm{HPO}_{4}, 1.5 \mathrm{mM} \mathrm{KH}_{2} \mathrm{PO}_{4}, \mathrm{pH} 7.1$ ), resuspended $\left(5 \times 10^{6}\right.$ cells $)$ in $0.5 \mathrm{~mL}$ of $45 \mathrm{mM}$ Tris-borate buffer- $1 \mathrm{mM}$ EDTA, $\mathrm{pH}$ 8.0, containing $0.25 \%$ Nonidet P-40 and $0.1 \%$ RNase A, incubated at $37^{\circ} \mathrm{C}$ for 30 minutes, treated with 1 $\mathrm{mg} / \mathrm{mL}$ of proteinase $\mathrm{K}$, and incubated for an additional 30 minutes at $37^{\circ} \mathrm{C}$. After incubation, 0.1 $\mathrm{mL}$ of loading buffer $(0.25 \%$ bromphenol blue, $30 \%$ glycerol) was added, and $40 \mu \mathrm{L}$ of the tube contents were transferred to the gel. Electrophoresis was performed on $1.6 \%$ agarose gel containing $0.5 \mu \mathrm{g} / \mathrm{mL}$ ethidium bromide at $80 \mathrm{~V}$ for 1-2 hours with a TAE (40 mM Tris-acetate, $1 \mathrm{mM}$ EDTA) running buffer. DNA was visualized under ultraviolet light and photographed.

\section{Evaluation of Antitumor Activity of Living System in i.p. Tumor Model}

$\mathrm{BALB} / \mathrm{c}$ mice (five mice per group) were injected i.p. with various numbers of Sp2/0-Ag 14 mouse myeloma cells suspended in $0.2 \mathrm{~mL}$ RPMI 1640 medium, and the mice were monitored daily for mortality.

\section{Statistical Analysis of Data}

The statistical comparisons were performed by the two-tailed Student's $t$ test.

\section{RESULTS}

\section{Comparison of the Effects of Active Mixtures Containing Their Components in the Maximum or Minimum Concentration Occurring in the Blood on $\mathrm{K562}$ and Sp2/0- Ag14 Cells}

In this experiment we investigated the effects of a maximal active mixture (the final concentration of its components in a well, corresponded to their maximum concentration existing in the blood), a minimal active mixture (containing its components in the minimum concentration found in the blood), and a control mixture on K562 and Sp2/0- 
Ag14 cells at different initial cell concentrations. We used control mixture in all experiments. The control mixtures contained compounds (amino acid, nucleobases, etc.) similar to the active mixtures. The components of control mixture were chosen from those compounds of 89 substances of the circulatory system that were found in our previous experiments ${ }^{37,38}$ ineffective at killing the cancer cells. The number of components, their concentration and, thus, the osmolarity of control mixture, corresponded to the active mixture (in this experiment, to the maximal active mixture).

Thus, the possibility that any effect induced by the active mixtures was the result of an osmotic effect, an aspecific overload of nutrients, an amino acid imbalance, or ammonium toxicity could be excluded. The maximum and minimum concentration in the blood of substances of active mixtures were taken from the scientific literature. ${ }^{43-50}$ The maximal active mixture was a model of an optimally operating defense system, while the minimal active mixture was a model of a poorly operating defense system. We used different starting cell concentrations because it can be assumed that the number of tumor cells arising simultaneously in different people may be different depending on the carcinogenic effects. Because some substances of the mixtures occur in the medium, we took the concentration of substances in the medium into account when the mixtures were prepared. The sum of the concentration of a given substance in the mixture and the concentration of the same compound in the medium, corresponded to the concentration of the given substance in the serum. The composition of the control mixture, as well as maximal and minimal active mixtures, are shown in Figure 1. L-ascorbate was highly toxic in vitro even when it was applied individually at a high concentration as its maximum concentration in the serum; therefore, we determined its nontoxic amount, and this was used in the maximal active mixture. The 2-deoxy-D-ribose, which was a component of active mixture in the previous experiments, ${ }^{37-40}$ was omitted from the active mixture because we could not find data about its serum concentration in the special literature. The cells were counted when the untreated cells proliferated to approximately $5 \times 10^{5}$. The results were expressed as a percentage of untreated cells. As it appears (Fig. 1), the maximal active mixture (black columns) had a significantly higher effect than the minimal active mixture (shaded columns) and killed all the K562 cells under 125
cells/mL starting cell concentration. Although the minimal active mixture had an effect as well at any initial cell concentration, it was ineffective in destroying all the cells even at 60 cells $/ \mathrm{mL}$ initial cell concentration. The control mixture (white columns) did not show a cell destructive effect. The results were similar in the case of Sp2/0Ag14 cells (data not shown). Adherent cells could not be used for these types of experiments because none of the cells, even the untreated ones, could grow under about 2000 cells/mL initial cell concentration (data not shown).

\section{Effect of the Amount of Active Mixture on the Length of Time Needed for Death of All K562 Cells}

In this experiment, the relationship between the concentration of active mixture (as a matter of fact, the concentration of its components) and the length of time needed for killing all the cells by the active mixture was investigated. The dilution of mixture was expressed in percentage of a starting mixture, called $100 \%$ mixture. The composition of $100 \%$ active mixture and $100 \%$ control mixture is shown in Figure 2. The length of time needed for cell death was detected for $100 \%$, $50 \%, 25 \%, 12.5 \%$, and $6.25 \%$ active mixtures. Because the components of active mixture contained by the medium cannot be diluted, we had to enhance the concentration of substances of the $100 \%$ active mixture. It was set as high as possible so that we could avoid the osmotic effect.

Practically, we took into account, for each component of active mixture, the 20 -fold amount of their maximum serum concentration (given in legend to Fig. 1). In contrast with the preceding experiment the amount of components contained by the medium was not taken into consideration when the mixture was prepared, because the components of medium cannot be diluted. On the other hand, it was not of importance from the point of view of this experiment, and it would have made the experiment unnecessarily complicated. Beside the 2-deoxy-D-ribose, the L-ascorbic acid sodium salt was also omitted from the mixture because it had, even alone, a high toxic effect on the given amount of cells and thus disturbed the experiment. In investigating the length of time of cell death, it was an important condition that any amount of active mixture, except for the lowest (the $6.25 \%$ mixture), should destroy all the cells. Because the death of all cells depends on the proportion of concentration of ac- 


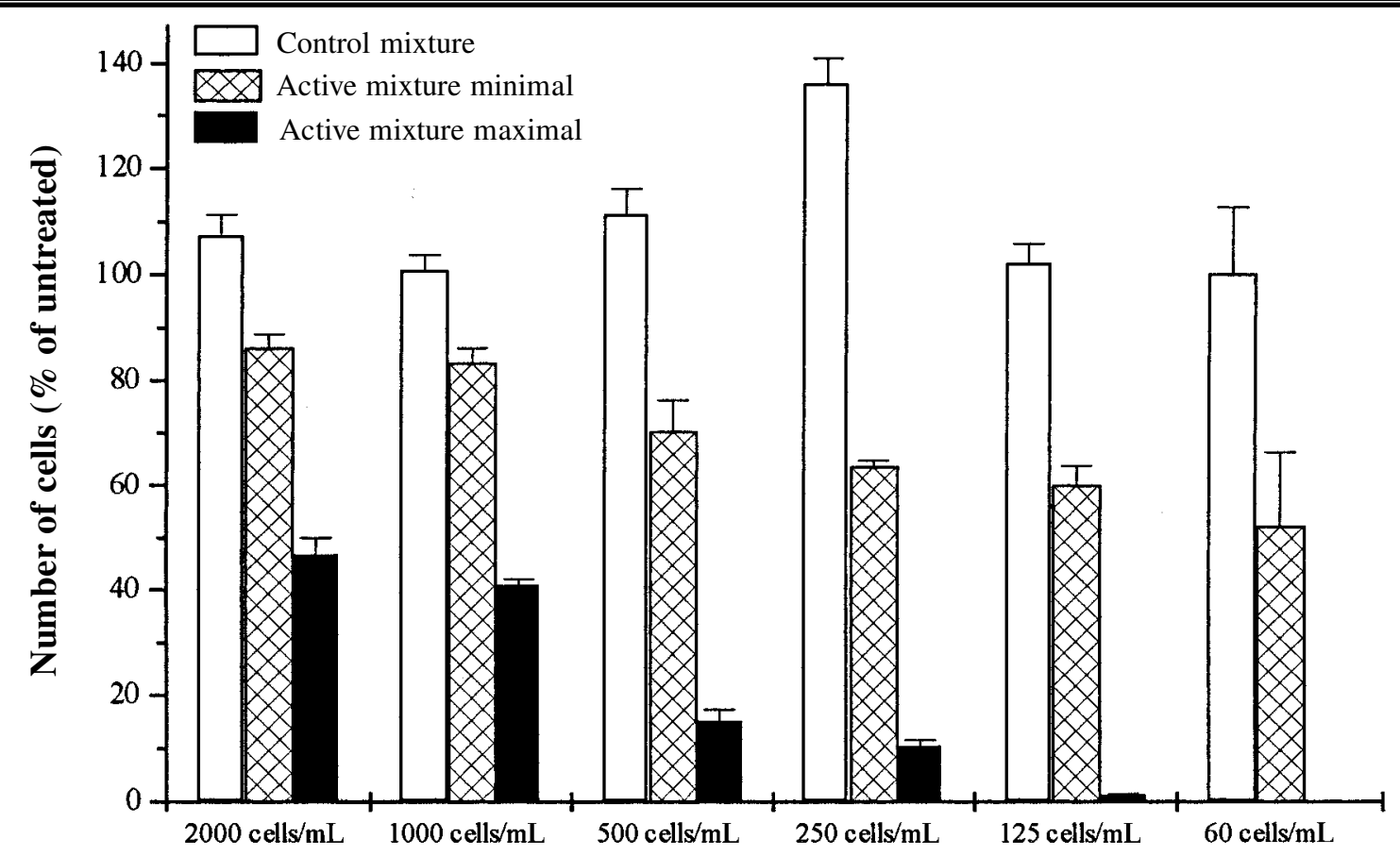

Number of cells inoculated

Figure 1. Effects of a maximal and a minimal active mixture on K562 cells. The maximal active mixture (black column) contained $67 \mu \mathrm{M}$ L(-)malic acid disodium salt, $151 \mu \mathrm{M}$ L-phenylalanine (+ $91 \mu \mathrm{M}$ in the medium), (1161 $\mu \mathrm{M} \mathrm{L-arginine} \mathrm{hydro-}$ chloride in the medium), $161 \mu \mathrm{M}$ L-histidine (+97 $\mu \mathrm{M}$ in the medium), $28 \mu \mathrm{M}$ L-tyrosine $(+110 \mu \mathrm{M}$ in the medium), $(101$ $\mu \mathrm{M}$ L-methionine in the medium), $122 \mu \mathrm{M}$ L-tryptophan $(+25 \mu \mathrm{M}$ in the medium $),(0.8 \mu \mathrm{M}$ d-biotin in the medium $), 195 \mu \mathrm{M}$ pyridoxine hydrochloride, $76 \mu \mathrm{M}$ L-ascorbic acid sodium salt, $1.1 \mu \mathrm{M}$ adenine hydrochloride, $0.8 \mu \mathrm{M}$ riboflavin $(+0.5 \mu \mathrm{M}$ in the medium), $122 \mu \mathrm{M} \mathrm{D}(+)$-mannose, $33.5 \mu \mathrm{M}$ hippuric acid sodium salt, and $4 \mu \mathrm{M}$ orotic acid sodium salt. The amount of a given component in the maximal active mixture and its amount in the medium (between brackets) together correspond to the maximum concentration of the given compound in the serum. The minimal active mixture (shaded column) contained $7.5 \mu \mathrm{M}$ L(-)malic acid disodium salt, $15 \mu \mathrm{M}$ L-ascorbic acid sodium salt, $0.6 \mu \mathrm{M}$ adenine hydrochloride, $39 \mu \mathrm{M} \mathrm{D}(+)$-mannose, $5.6 \mu \mathrm{M}$ hippuric acid sodium salt, and $1.1 \mu \mathrm{M}$ orotic acid sodium salt. The other compounds were contained by the medium. The control mixture (white column) contained $67 \mu \mathrm{M}$ succinic acid disodium salt, $151 \mu \mathrm{M}$ L-serine, $161 \mu \mathrm{M} \mathrm{L-valine,} 28 \mu \mathrm{M}$ L-alanine, $122 \mu \mathrm{M}$ L-proline, $195 \mu \mathrm{M}$ niacin, $76 \mu \mathrm{M}$ folic acid sodium salt, $1.1 \mu \mathrm{M}$ hypoxanthine, $33.5 \mu \mathrm{M}$ betaine, and $4 \mu \mathrm{M}$ uracil. The usual other two components (D- $(+)$-glucose and D-pantothenic acid hemicalcium salt) were contained by the medium. The concentrations are given as final concentrations in a well. The results are expressed as percentage of untreated cells. The values are mean \pm standard error (bars) for three independent experiments.

tive mixture and cells, on the basis of the previous experiment the concentration of cells was set to 300 cells $/ \mathrm{mL}$.

Because it was expected that the concentration of cells do not increase during the experiment, and the cells die under shorter and shorter time intervals as the amount of active mixture increases, the result could not be evaluated by the usual methods. Thus, the cell death was detected visually by invert microscope. The microplates were monitored every day at the same time, and the day was taken as the time of death when all the cells died in every parallel well (six) in which the cells were treated by the same amount of active mixture. It can be seen (Fig. 2) that as the amount of active mixture and thus the mixtureto-cell ratio increased, the length of time needed for death of the same number of cells decreased. Because the cells were not destroyed by the $6.25 \%$ active mixture, or by any amount of control mixture, the data concerning their effects could not be plotted in Figure 2 .

\section{Effect of the Total Number of Cells and the Size of Cultural Surface on the Survival of K562 Cells}

To find out whether the total number of cells or the size of cultural surface can influence the effect of active mixture, we performed experiments 


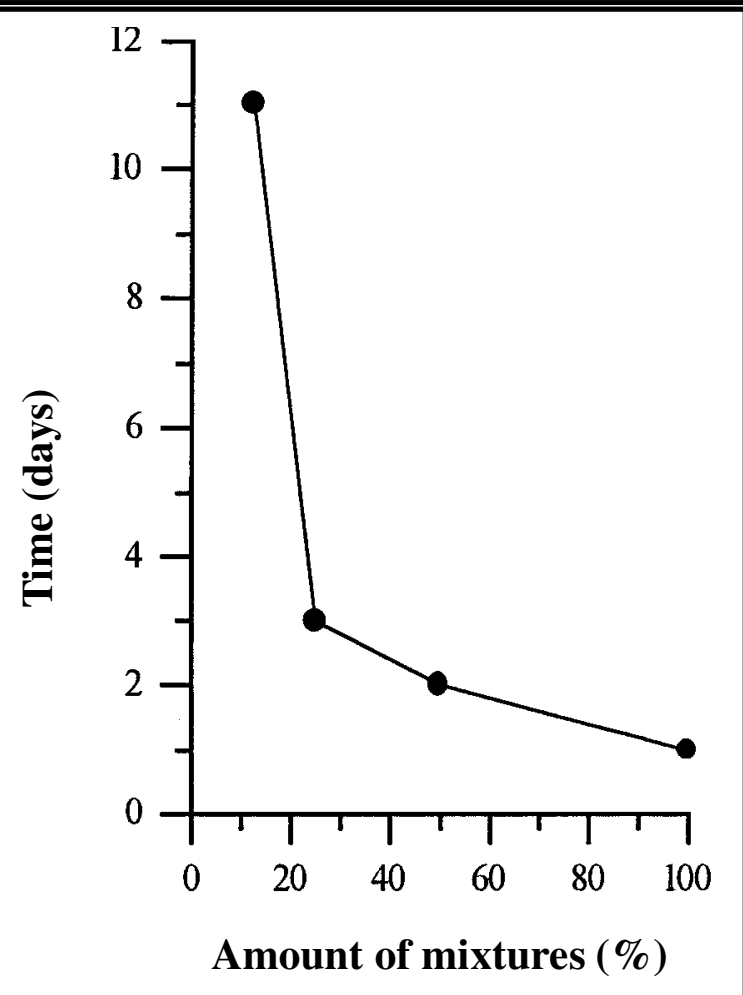

Figure 2. Effect of active mixture on the length of time needed for death of all K562 cells. The concentration of cells was 300 cells $/ \mathrm{mL}$. The $100 \%$ active mixture contained 1.34 $\mathrm{mM} \mathrm{L}(-)$ malic acid disodium salt, $4.84 \mathrm{mM}$ L-phenylalanine, $3.48 \mathrm{mM}$ L-arginine hydrochloride, $4.9 \mathrm{mM}$ L-histidine, 2.76 $\mathrm{mM}$ L-tyrosine, $1.34 \mathrm{mM}$ L-methionine, $2.94 \mathrm{mM}$ L-tryptophan, $0.002 \mathrm{mM}$ d-biotin, $3.9 \mathrm{mM}$ pyridoxine hydrochloride, $0.022 \mathrm{mM}$ adenine hydrochloride, $0.026 \mathrm{mM}$ riboflavin, $2.44 \mathrm{mM} \mathrm{D}(+)$-mannose, $0.67 \mathrm{mM}$ hippuric acid sodium salt, and $0.08 \mathrm{mM}$ orotic acid sodium salt. The $100 \%$ control mixture contained $1.34 \mathrm{mM}$ succinic acid disodium salt, $4.84 \mathrm{mM} \mathrm{L}$-serine, $3.48 \mathrm{mM} \mathrm{L}$-asparagine, $4.9 \mathrm{mM} \mathrm{L}-$ valine, $2.76 \mathrm{mM}$ L-alanine, $1.34 \mathrm{mM}$ glycine, $2.94 \mathrm{mM} \mathrm{L-}$ proline, $0.002 \mathrm{mM}$ thiamine hydrochloride, $3.9 \mathrm{mM}$ niacin, $0.022 \mathrm{mM}$ hypoxanthine, $0.026 \mathrm{mM}$ D-pantothenic acid hemicalcium salt, $2.44 \mathrm{mM}$ - $(+)$-glucose, $0.67 \mathrm{mM}$ betaine and $0.08 \mathrm{mM}$ uracil. The concentrations are given as final concentrations in a well.

where the cells were grown in 96-well or 24-well plates or Petri dishes. The total starting amount of K562 cells was $2 \times 10^{4} /$ well in the 96-well plate, $8 \times 10^{4} /$ well in the 24 well plate, and $2 \times$ $10^{6}$ in the Petri dishes. In every experiment the concentration of cells was $8 \times 10^{4}$ cells $/ \mathrm{mL}$ medium. The results were independent from the total number of cells and the size of cultural surface. This depended only on the proportion of concentration of the active mixture and the cells (data not shown).

\section{Visual Investigation of the Effect of Active Mixture on the Survival of K562 Cells in the Case of Decreasing Mixture- to-Cell Ratio}

In the current experiment we investigated visually, by invert microscope, what happens when the cells are submitted to a diminishing amount of active mixture (the mixture-to-cell ratio decreases). This was the model of a declining defense system. We used the same $100 \%$ active mixture and $100 \%$ control mixtures as in the second experiment (Fig. 2). To be able to investigate the effect of diminishing active mixture, we had to set the cell concentration higher than in the second experiment. Taking into consideration that the concentration of cells destroyed totally by the maximal active mixture in the first experiment (Fig. 1) was about 100 cells $/ \mathrm{mL}$, and that the $100 \%$ active mixture in this experiment is a 20 -fold amount of the maximal active mixture used in the first experiment, the cell concentration was set to 20 -fold of 100 cells $/ \mathrm{mL}$; namely, to 2000 cells $/ \mathrm{mL}$. This amount of cells was exposed to the effect of $100 \%$ control mixture, or $100 \%, 50 \%, 25 \%$ or $12.5 \%$ active mixture. The cultures were photographed directly from the culture plates, using an inverted phase contrast microscope. The photographs taken after an 8-day incubation period (Fig. 3) illustrate the results.

It can be seen that the untreated cells (Fig. 3A) and the cells treated by the $100 \%$ control mixture (Fig. 3B) proliferated to a high number of cells during the 8 days, and all of the cells were alive and well conditioned at the end of experiment. The bulk of cells shown in the photos arose from some mother cells. In contrast with that, all the cells treated with the $100 \%$ active mixture were killed (Fig. 3C) without dividing even once. When the $50 \%$ active mixture was applied (Fig. 3D), the cells also died, but some of them could divide once before their death and one of those seen in the photo could divide twice. Figure $3 \mathrm{E}$ shows the cells when they were exposed to the $25 \%$ active mixture. It can be seen in the photograph that at this ratio of mixture and cells the division and death of cells occurring simultaneously were approximately in equilibrium. The death of cells seems apoptotic because of blebbing cells and apoptotic bodies (arrows). When the amount of active mixture was further decreased (to $12.5 \%$ ), proliferation overtook cell death (Fig. 3F). However, it is important to emphasize that some dying and dead cells can be seen in the photo, and the cell number is significantly lower than the number of untreated (Fig. 3A) and the $100 \%$ control-mixture treated cells (Fig. 3B). 


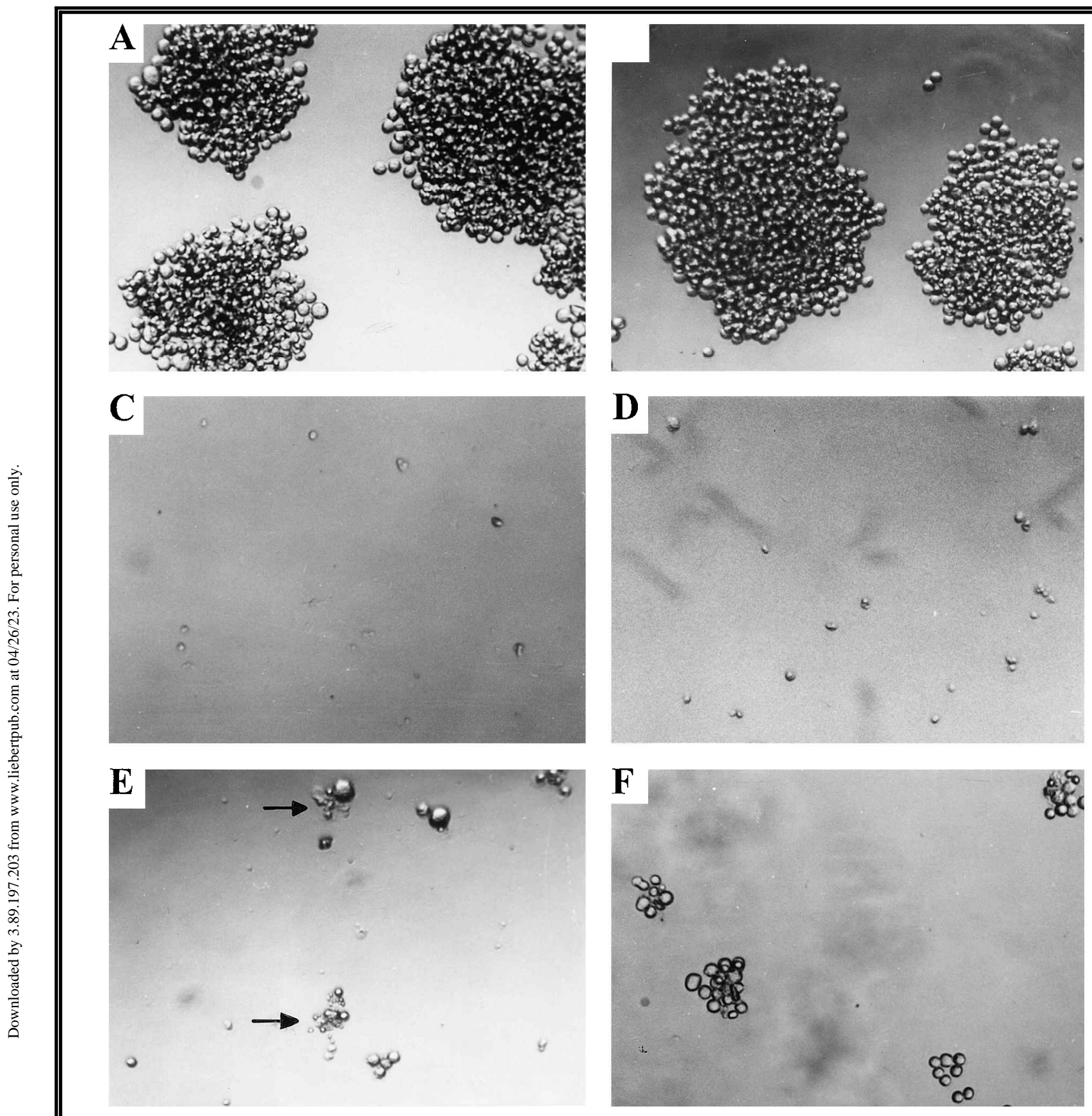

Figure 3. Visual comparison of the effect of active mixture and control mixture on K562 cells. The concentration of cells was 2000 cells $/ \mathrm{mL}$. The composition of the $100 \%$ active mixture and $100 \%$ control mixture are given in the legend of Figure 2 . Cells were incubated in the growth medium without $(\mathbf{A})$ or with $100 \%$ control mixture $(\mathbf{B})$ or $100 \%(\mathbf{C}), 50 \%(\mathbf{D}), 25 \%(\mathbf{E})$, or $12.5 \%$ (F) active mixture for eight days. Arrows (E) show blebbing cells and apoptotic bodies.

Investigation of the Apoptosis-Inducing Effect of Active Mixture on K562 Cell Line Detected by Gel Electrophoresis

We used gel electrophoresis to investigate whether the death of cells in the previous exper- iment (Fig. 3E) was apoptotic. Therefore, the cell concentration was also set to 2000 cells $/ \mathrm{mL}$ as in the previous experiment. The K562 cells treated with the same $25 \%$ active mixture as in the preceding experiment (Fig. 3E) show fragmentation of DNA into endonucleosome-sized units char- 
acteristic of apoptotic cell death (Fig. 4). In contrast, a ladder-like pattern of DNA fragmentation cannot be seen in the case of untreated cells and in the case of cells treated with control mixture.

\section{Investigation of the Antitumor Activity of the Living System Inoculating Various Numbers of Tumor Cells}

All the mice given injections of $5 \times 10^{3}$ or less Sp2/0-Ag14 mouse myeloma cells survived. They showed no evidence of i.p. tumor growth when sacrificed 100 days following injections of the cells (Fig. 5). Inoculating $1 \times 10^{4}$ or more cells, every mouse died (Fig. 5).

\section{DISCUSSION}

As per our starting hypothesis, a passive antitumor defense system (PADS) exists in the living

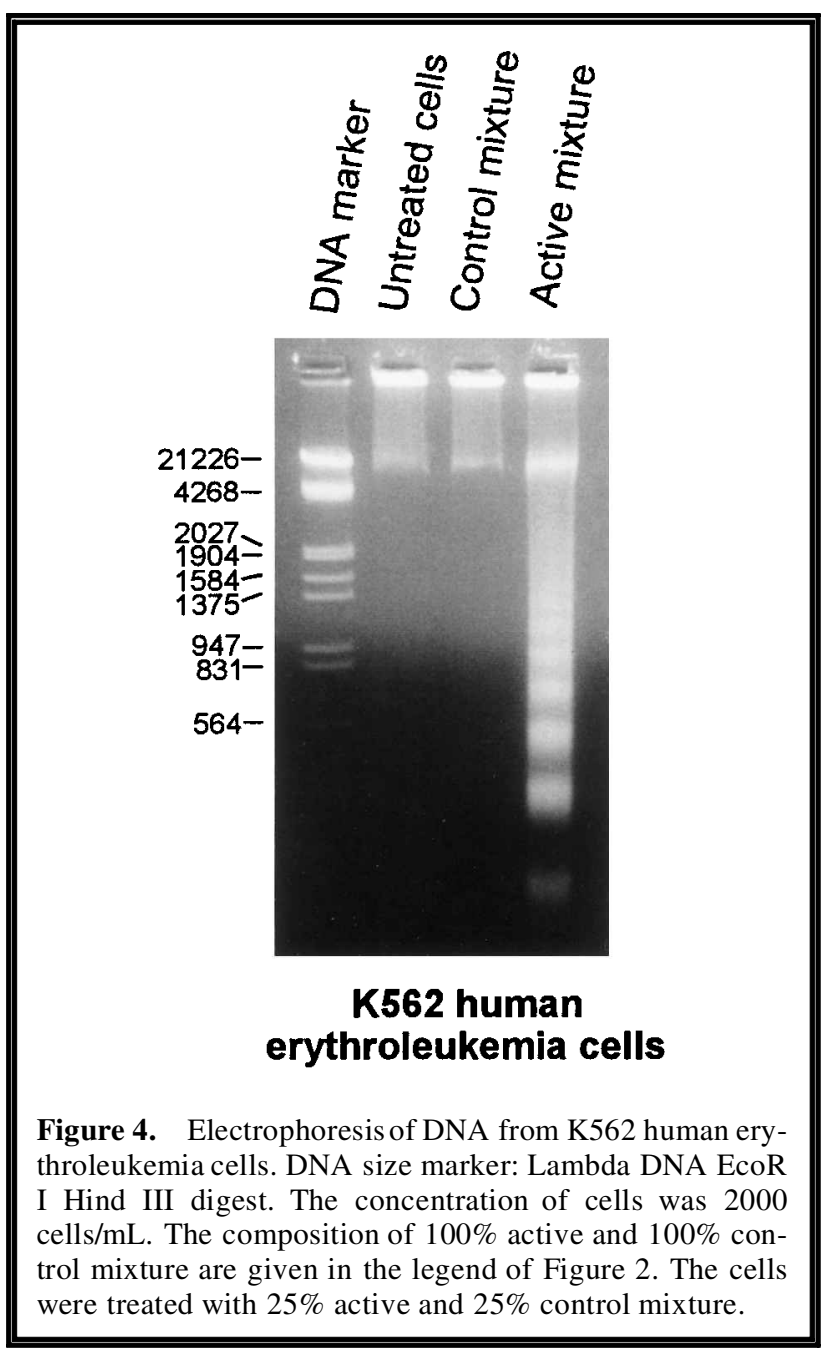

system, besides the known immune mechanisms, and the effective agents of this defense are certain small substances of the circulatory system. The supposed operation of the PADS is illustrated by hypothetical figures (Fig. 6).

The concentration of substances of PADS continuously changes in the circulatory system depending on nutrition, age, lifestyle, and so forth, as shown by the lines. The bars symbolize the amount of arising tumor cells. If the number of arising cancer cells remains under a critical value, then the concentration of substances of PADS existing in the environment of given cells is satisfactorily high, in order to destroy all the arising cells (Fig. 6A). According to our thinking, this happens in the majority of the population during their lifetime. If the number of tumor cells arising simultaneously exceeds a critical value because of some reason (e.g., strong carcinogenic effects, viruses, hereditary predisposition to cancer, etc.), then the tumor develops because above the critical value the divisions of cells overcompensate for the killing of cells by the defense mechanism (Fig. 6B).

The other way a tumor develops is by the decrease of concentration of the above-mentioned substances in the circulatory system, in consequence of some reason (e.g., malnutrition, disease, stress, etc.) and thus the impairment of effectiveness of the PADS (Fig. 6C). Although in this case no more tumor cells arise than in the majority of the population, the number of cells can still reach the critical value because of the low concentration of the defense molecules. Obviously, the level of defense never decreases to zero because the majority of substances taking part in it have endogenous sources, only it cannot always operate optimally.

To verify the above mechanism, the effect of active mixtures containing their components at concentrations corresponding to the maximum or minimum concentration of the given components in the serum, was investigated on K562 and Sp2/0-Ag14 tumor cells (Fig. 1). When the substances of active mixture were used in their maximum concentration existing in the blood (maximal active mixture: the model of optimally operating defense system) and the tumor cells at different (decreasing) initial cell concentration were subjected to the effect of this mixture (Fig. 1 ), we could determine the critical cell number for this condition. This critical cell number was between 125 and 60 cells $/ \mathrm{mL}$ (about 100 cells $/ \mathrm{mL}$ ). It can be seen (Fig. 1, black columns) 


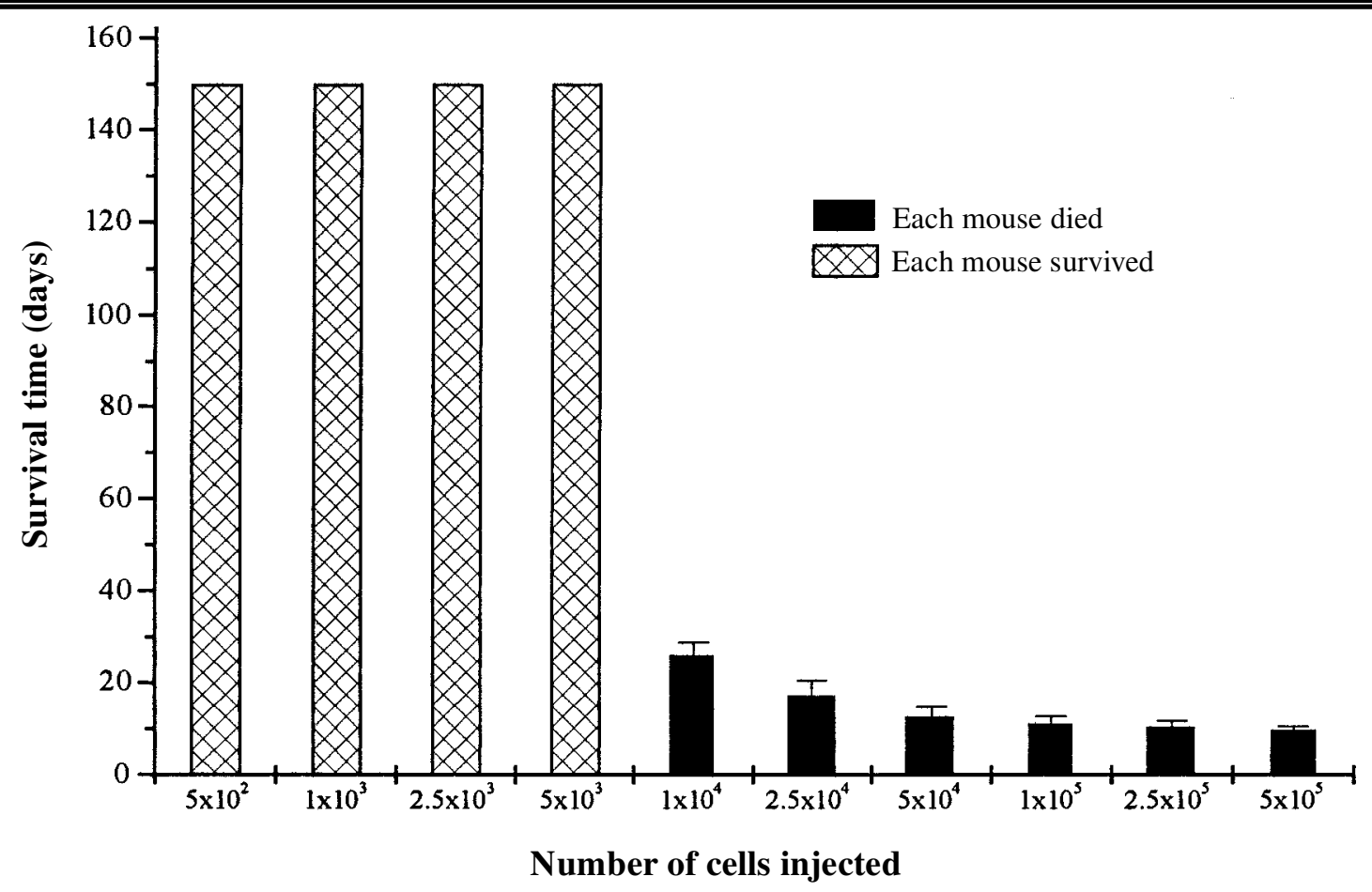

Figure 5. Survival of Sp2/0-Ag14 mouse myeloma cells in mice. Mice were given injections i.p. of the indicated various numbers of cells and were monitored for survival. The values are mean \pm standard error (bars) for five mice.

that below this critical value all the cells were killed by the maximal active mixture. This corresponds to the condition that occurs (according to our hypothesis) in the majority of the population during their lifetime (shown in the hypothetical Fig. 6A) when the number of cancer cells arising is less than the critical value. Although the maximal active mixture could not destroy all the tumor cells above the critical value (above about 100 cells $/ \mathrm{mL}$ ) because the cell death was overcompensated by the cell division, it had some cytotoxic effect on the cells at any initial cell concentration compared to the control mixture. $\mathrm{Ob}$ viously, the proliferation-diminishing effect decreased as the initial cell concentration increased. This situation exists in the living system as is shown in the hypothetical Figure 6B when the cell number gets above the critical value, and thus the tumor develops.

According to an old-standing clinical observation, ${ }^{51}$ recidivism does not occur in the case of hematological tumors if the cell number can be decreased by the usual treatment to $10^{6}-10^{5}$, because the defense mechanisms of living systems can destroy the remaining cells. Notwithstanding that the observations of cell culture experiments cannot be adapted directly to living systems, it is interesting to make a calculation with our results since we used a human erythroleukemia cell line. In our experiment (Fig. 1) the active mixture killed about 100 cells/mL; that is, 100,000 cells/L. Taking as an average about 5 liters of blood in a person, the total number of cells is about $5 \times 10^{5}$. This value corresponds to the cell numbers that can be destroyed by the living system. It is not probable that the known immune system kills the cells remaining after treatment, because the majority of clinically relevant tumors are not or only weakly immunogenic, and the treatment generally decreases the effect of the known immune system. If we suppose, in spite of the above, that the known immune system kills the remaining cells, then the fact that it can destroy only a limited number $\left(10^{6}-10^{5}\right)$ of cancer cells conflicts with the fact that the known immune system is an activable mechanism.

The result of next in vivo experiment (Fig. 5) raises a similar contradiction. Mice given injections of $5 \times 10^{3}$ or less Sp2/0-Ag14 cells showed no evidence of i.p. tumor growth. Injecting 2 -fold $\left(1 \times 10^{4}\right)$ or more amount of cells, tumors developed in all the rodents in spite of the fact that 
QZA Amount of arising tumor cells

Level of substances of defense system

A

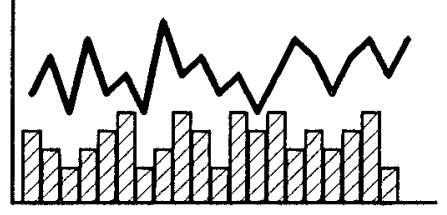

$\mathrm{B}$

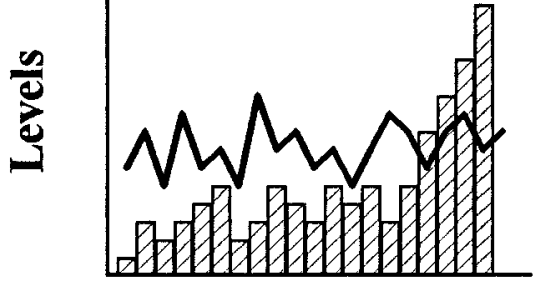

C

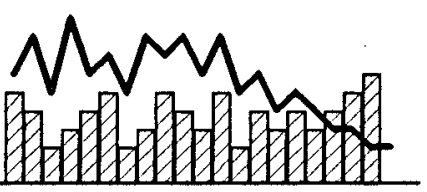

Time

Figure 6. Hypothetical figures to illustrate the supposed operation of the passive antitumor defense system. The figure shows the well operating defense system (A), and the passing of the critical cell number in consequence of too many cancer cells arising; (B) or decreasing concentration of the defender substances $(\mathbf{C})$.

in these mice the immune system might act. A similar finding was reported in another paper ${ }^{52}$ about another cell line. A similar experiment done earlier by us, for another reason, ${ }^{37,40}$ gave the same result. The sharp limit observed (Fig. 5) between the cell number causing the development of tumor and the cell number showing no evidence of tumor growth is also rather strange from the point of view of the known activable immune system. If the known immune system can kill $5 \times$ $10^{3}$ or less cells, why can't the same immune system kill $1 \times 10^{4}$ (or more) cells? If it can destroy
$10^{6}-10^{5}$ hematological cancer cells, why can it not destroy more cells? These questions become answerable only if we accept that in the living system the PADS and not the known immune system eliminates the cancer cells, because the former has a limited activity that cannot be increased by any signal of the living system (passive), and therefore it can kill only a certain number of cancer cells (under the critical cell number). Namely, in the case of $5 \times 10^{3}$ or fewer cells (or less than $10^{6}$ cells) the cell number is under the critical value, and all the cells are destroyed by PADS. In the case of $1 \times 10^{4}$ or more cells (or more than $10^{6}$ cells), the cell number is above the critical value and the cell division overcompensates for the amount of cell death. Thus, more cells arise than die and consequently the tumor develops.

When we increased the concentrations of substances of PADS in the circulatory system of $\mathrm{BALB} / \mathrm{c}$ mice by injections of active mixture, ${ }^{37}$ the survival time of mice injected i.p. with $5 \times 10^{4}$ $\mathrm{Sp} 2 / 0-\mathrm{Ag} 14$ cells increased significantly. We determined the number of tumor cells present in the ascitic fluid of treated and control mice after finishing treatment. ${ }^{37}$ The significant $(p<0.001)$ difference between mean cell number of control $\left(9.68 \times 10^{7}\right)$ and treated group $\left(10.8 \times 10^{5}\right)$ excludes the possibility that the increase of survival time was caused only by a roborating effect of substances of active mixture. In another experiment ${ }^{37}$ the treatment with active mixture slowed down the growth of solid tumors significantly. These observations demonstrate that the activity of PADS can be increased from outside. It obviously results from this that the PADS always has an effect in the living system, because the components of active mixture always exist in the circulatory system, only in lower concentrations than in the above experiments.

It can be seen in Figure 1 that the minimal active mixture (the model of a poorly operating defense system) also had an effect on the tumor cells at any initial cell concentration. Obviously, its effect was lower than the effect of maximal active mixture; what is more, the minimal active mixture could not kill all the cells even at the lowest initial cell concentration. That means, if the defense system cannot operate optimally, then the tumor develops even at low concentrations of arising tumor cells as is illustrated in the hypothetical Figure 6C. This happens when the amount of defense substances decreases for some reason. The finding that the control mixture had no cytotoxic effect on tumor cells at all (Fig. 1), demonstrates that the cell-killing effect (the de- 
fense) is a fundamental feature of the given substances selected experimentally from the compounds of the circulatory system. The adherent cells could not be used in similar experiments because they could not proliferate at the above-mentioned low cell concentration, even in the absence of any treatment. However, the results of our previous experiments ${ }^{37,38,40}$ performed with a higher number of adherent cells $(40,000$ cells/mL) and obviously with a higher amount of active mixture than in the present study, and our in vivo experiment with solid tumors, ${ }^{37}$ make it probable that the substances of PADS can kill, in the living system, a certain number of this type of cells also.

It was demonstrated that the effect of active mixture was independent from the total number of cells and the size of cultural surface; it only depended on the proportion of concentration of active mixture and concentration of cells (data not shown).

The question may be raised whether the total amount or the concentration of the given compounds in the circulatory system has higher importance from the point of view of the PADS. The experimental results show (Fig. 2) that the length of time needed for death of the same amount of cells decreases as the concentration of active mixture increases. This means that the rate of cell death depends on the concentration of the active mixture. Obviously, the rate of cell division is conditioned by the concentration of the cells. To our thinking, in the living system cell division and cell death compete with each other ceaselessly. Their relative rate determines whether the tumor does or does not develop. At the critical value, the rate of division and the rate of death are equal. Below the critical value, the rate of cell death is higher than the rate of division and so all the cells die (Fig. 1, below 125 cells $/ \mathrm{mL}$ ), but above the critical value the rate of cell division is higher than the rate of death and the tumor develops (Fig. 1, above 125 cell/mL and in any cases of minimal active mixture). This speculation fits in well with the opinion of oth$\mathrm{ers}^{53}$ that the growth of a tumor is regulated not only by the rate at which tumor cells divide, but more importantly by the rate at which they die. As appears in Figure 2, the $6.25 \%$ of active mixture could not kill all the cells because the rate of cell death was at such a low level that it was already overcompensated by the rate of cell division. At $12.5 \%$ of active mixture the rate of cell death was only barely higher than the rate of cell division and thus, the death of all the cells needed
11 days. In the case of $25 \%$ (or higher) active mixture, the rate of cell death was significantly higher than the rate of cell division; therefore, only 3 days (or less) were needed for death of all the cells. The above findings indicate the necessity of keeping the optimal concentration of substances of the defense system in the blood every time.

The importance of that is further corroborated by the experiment (Fig. 3) in which we investigated visually (by photos) what happens with the tumor cells when the effectiveness of defense is shifted from the optimally operating to the poorly operating condition. It may be seen in the photos of Figure 3 that as the amount of active mixture decreased (in other words, as the effectiveness of the defense system declined) the division of K562 cells became more and more dominant compared to the cell death. While in the case of $100 \%$ active mixture all the cells were destroyed before they could divide only once (Fig. 3C), in the case of $50 \%$ active mixture some cells could already divide once before their death (Fig. 3D). As the amount of active mixture decreased further (to $25 \%$ ), the rate of cell division became commensurable with the rate of cell death (Fig. 3E). This is the point at which the mixture-to-cell ratio is about the critical value, and the cell division and cell death occurring simultaneously are in equilibrium. It can be seen clearly in the photo that cell death is accompanied by cell blebbing and formation of apoptotic bodies (Fig. 3E; arrows), which has been discovered to be a late event in apoptosis and a marker of it. K562 cells grown in the same condition show fragmentation of DNA into endonucleosome-sized units demonstrated by agarose gel electrophoresis (Fig. 4). This corroborates that the apoptotic death of cells can be seen in the photo (Fig. 3E; arrows). The above results are consistent with our previous findings demonstrating that the active mixture induced the apoptosis of tumor cells. ${ }^{39,40}$ If in this situation (Fig. 3E) in the living system, the concentration of substances of defense mechanism gets higher (e.g., due to nutrition or a preventive medicine containing the mentioned substances), then the equilibrium of death and division shifts to direction of death (to the direction of previous state as shown in the Fig. 3D) and all the tumor cells will die. However, if the concentration of components of the defense system further decreases (e.g., in consequence of stress, illness, malnutrition) then the cell division will overcompensate the cell death and the tumor devel- 
ops, it can be seen in Figure 3F. It is important to emphasize that in the last photo (Fig. 3F), some caduceus and dead cells can be seen and the number of cells is significantly lower than the number of cells untreated or treated by the control mixture (Fig. 3A and 3B). This means that the PADS has an influence even in the presence of a growing tumor, because the tumor cells are always subjected to the effect of the "defender" molecules, only in the case of a growing tumor the rate of cell division is higher than the rate of cell death. This statement is supported by the observation that the maximal active mixture slowed down the proliferation of cells compared to untreated cells above 125 cells/mL cell concentration (Fig. 1), and that in our in vivo experiments, ${ }^{37}$ although the concentration of active mixture ensured by the treatment was not enough to kill all the tumor cells and cure the animals, could still eliminate more than $99 \%$ of tumor cells injected i.p. and increase the survival time of mice, as well as slowing down significantly the growth of solid tumors in the treated animals.

Once the existence of the PADS has been accepted, various observations can be explained. For example, the monoclonality of the majority of tumors cannot be explained by the effect of the known immune system, because the clonal origin of tumors is observed in immunosuppressed patients. ${ }^{54}$ It can only be elucidated by the existence of a critical cell number and a passive defense mechanism possessing a relatively constant level of activity. This can be demonstrated clearly in the above photos. If the level of defense is high enough or the number of arising cell is low, in other words, the rate of cell death is much higher than the rate of cell division then all the cells die before they can divide only once. This situation occurs in Figure 3C. As the number of arising cancer cells (in other words, the rate of cell division) increases or the level of defense (in other words, the rate of cell death) declines, the probability rises that some of the cancer cells can divide once before they die, similarly as in Figure 3D. The number of cells that can divide twice, three times, and so on, decreases considerably. In the above-mentioned photo (Fig. 3D), many cells can be seen that could divide once before death, but only one cell can be seen that could divide twice. The more cancer cells arise (e.g., because of carcinogenic effect) or the lower the level of defense (e.g., because of malnutrition), the higher the probability that at least one of the cells can divide so many times that the number of its daughter cells reaches the critical value. Obviously, if the number of arising cells is very high due to determinants such as hereditary susceptibility, then the probability increases that the number of daughter cells of more than one original cell can reach the critical value, and the tumor will be polyclonal. This is in accordance with the observation that the majority of human tumors are of monoclonal origin excepting, for example, hereditary tumors. ${ }^{27,55}$ The majority of tumors in animals also show monoclonality. 54

There are other observations (e.g., contradiction in the incidence of cancer with advancing age and in AIDS, the observations about the effects of nutrition and malnutrition, etc.) that can also be explained only if we accept the existence of PADS as it is detailed in our theoretical (epidemiological) paper. ${ }^{41}$

Finally, it was reported earlier that many substances of PADS, namely ascorbic acid, ${ }^{56,57}$ arginine, ${ }^{58}$ 2-deoxy-D-ribose, ${ }^{59}$ mannose, ${ }^{60}$ orotic acid, ${ }^{61}$ pyridoxine, ${ }^{62}$ riboflavin, ${ }^{63}$ and tyrosine,${ }^{64}$ had antitumor effect when they were used singly. Taking our experimental findings into account that the above substances, moreover, could increase the effect of each other on tumor cells synergistically, ${ }^{37-40}$ the above observations about the effect of the same substances singly strongly support the existence of the PADS and corroborate our results.

Investigation (by DNA microarray, real-time quantitative PCR, nuclear magnetic resonance [NMR], etc.) of the mechanism of cell death (apoptosis) induced by the substances of PADS is in progress in our laboratory.

From the knowledge of substances taking part in the defense system the possibility arose of practical usage as medication, which has been protected by patent in Hungary ${ }^{65}$ and in many other countries. On the basis of patents two products $\left(\right.$ Culevit ${ }^{\circledR}$ tablets and Culevit ${ }^{\circledR}$ cream [Culevit, Budapest, Hungary]) have been developed. The development of an infusion (Culesol) is in preclinical phase.

\section{ACKNOWLEDGMENTS}

The author thanks Prof. Dr. B. Sümegi, Dr. L. Lex, and Dr. M. Bors for continuous support, and Dr. F. Gallyas, Jr. for critical reading of manuscript. The author also thanks H. Halász for excellent technical assistance, and Prof. Dr. P. Németh for his help. 


\section{REFERENCES}

1. Fauci AS. The human immunodeficiency virus: Infectivity and mechanisms of pathogenesis. Science 1988; 239:617.

2. Reif AE. Immunosurveillance reevaluated in light of AIDS. In: Lapis K, Eckhardt S, eds. Lectures and Symposia 14th International Cancer Congress. Budapest, Hungary, 1986. Basel: Karger, Budapest: Akadémiai Kiadó, 1987:321.

3. Kalish RS, Schlossman SF. The T4 lymphocyte in AIDS. N Engl J Med 1985;313:112.

4. Zunich KM, Lane HC. Immunologic abnormalities in HIV infection. Hematol Oncol Clin N Am 1991;5:215.

5. Gootenberg JE, Stewart CL, Vetro SW, Bellanti JA. Lack of graft rejection in a renal transplant recipient with AIDS. Ann Allergy 1991;67:123.

6. Rabkin CS, Biggar RJ, Horm JW. Increasing incidence of cancers associated with the human immunodeficiency virus epidemic. Int J Cancer 1991;47:692.

7. Rabkin CS, Blattner WA: HIV infection and cancers other than non-Hodgkin lymphoma and Kaposi's sarcoma. Cancer Surv 1991;10:151.

8. Casabona J, Melbye M, Biggar RJ, and the AIDS Registry Contributors. Kaposi's sarcoma and non-Hodgkin's lymphoma in European AIDS cases. No excess risk of Kaposi's sarcoma in Mediterranean countries. Int J Cancer 1991;47:49.

9. Schechter MT, Marion SA, Elmslie KD, et al. Geographic and birth cohort associations of Kaposi's sarcoma among homosexual men in Canada. Am J Epidemiol 1991;134:485.

10. Rabkin CS, Goedert JJ, Biggar RJ, Yellin F, Blattner WA. Kaposi's sarcoma in three HIV-infected cohorts. J Acquir Immune Defic Syndr 1990;3(suppl. 1):S38.

11. Mueller BU, Butler KM, Higham MC, et al. Smooth muscle tumours in children with human immunodeficiency virus infection. Pediatrics 1992;90:460.

12. Levin MA. Acquired immunodeficiency syndrome malignancies. Semin Oncol 2000;27:389.

13. Weiss RA. Viruses, cancer and aids. FEMS Immunol Med Microbiol 1999;26:227.

14. Myers AM, McCarty E, Abernathy C, Moore GE. Breast cancer in a man with HIV infection. AIDS 1992; 6:1218.

15. Hokama Y, Nakamura RM. Immunology and Immunopathology. Boston: Little, Brown \& Co., 1982.

16. Prehn LM. Immunostimulation of highly immunogenic target tumor cells by lymphoid cells in vitro. J Natl Cancer Inst 1976;56:833.

17. Prehn RT. The immune reaction as a stimulator of tumor growth. Science 1972;176:170.

18. Prehn RT. Stimulatory effects of immune reactions upon the growths of untransplanted tumors. Cancer Res 1994;54:908.

19. Fodstad Ø, Hansen CT, Cannon GB, et al. Lack of correlation between natural killer activity and tumour growth control in nude mice with different immune defects. Cancer Res 1984;44:4403.
20. Le Lann-Terrisse AD, Fournié GJ, Benoist H. Nucleosome-dependent escape of tumour cells from naturalkiller-mediated lysis: Nucleosomes are taken up by target cells and act at a postconjugation level. Cancer Immunol Immunother 1997;43:337.

21. Hamburger AW, White CP. Growth factors for human tumor clonogenic cells elaborated by macrophages isolated from human malignant effusions. Cancer Immunol Immunother 1986;22:186.

22. Sheid B. Angiogenic effects of macrophages isolated from ascitic fluid aspirated from women with advanced ovarian cancer. Cancer Lett 1992;62:153.

23. Al-Sarireh B, Eremin O. Tumour-associated macrophages (TAMS): Disordered function, immune suppression and progressive tumour growth. J R Coll Surg Edinb 2000;45:1.

24. Walker PR, Saas P, Dietrich P. Role of Fas ligand (CD95L) in immune escape. The tumour cell strikes back. J Immunol 1997; 158:4521.

25. Hewitt HB. Failure of cancer research. J R Soc Med 1991;84:321.

26. Steel GG. Cell loss as a factor in the growth rate of human tumours. Eur J Cancer 1967;3:381.

27. Stockdale FE. Cancer growth and chemotherapy. In: Rubenstein E and Federman DD, eds. Scientific American Medicine. New York: Scientific American Inc., 1984:1.

28. Liotta LA. The biology of metastasis. In: Kelley WN, DeVita VT, DuPont HL, et al. eds. Textbook of Internal Medicine. Philadelphia: JB Lippincott Co., 1989:1144.

29. Rabkin CS, Biggar RJ, Melbye M, Curtis RE. Second primary cancers following anal and cervical carcinoma: Evidence of shared etiologic factors. Am J Epidemiol 1992;136:54.

30. Kitamura K, Mitsudomi T, Ishida T, et al. Adenocarcinoma and squamous cell carcinoma in the same lobe of the lung. Respiration 1991;58:226.

31. Wallach DFH. Membrane permeability. In: Wallach DFH, Schmidt-Ullrich R, eds. Membrane Molecular Biology of Neoplastic Cells. Amsterdam: Elsevier Scientific Publishing Co., 1975:293.

32. Cameron E, Pauling L, Leibovitz B. Ascorbic acid and cancer: A review. Cancer Res 1979;39:663.

33. Medina MÁ, Márquez J, Núnez de Castro I. Interchange of amino acids between tumor and host. Biochem Med Metab Biol 1992;48:1.

34. Traut TW. Physiological concentrations of purines and pyrimidines. Mol Cell Biochem 1994;140:1.

35. Kubota R, Kubota K, Yamada S, et al. Methionine uptake by tumor tissue: A microautoradiographic comparison with FDG. J Nucl Med 1995;36:484.

36. Hübner KF, Purvis JT, Mahaley SM Jr, et al. Brain tumor imaging by positron emission computed tomography using ${ }^{11} \mathrm{C}$-labeled amino acids. J Comput Assist Tomogr 1982;6:544.

37. Kulcsár Gy. Inhibition of the growth of a murine and various human tumor cell lines in culture and in mice by mixture of certain substances of the circulatory system. Cancer Biother 1995;10:157. 
38. Kulcsár G. Synergistic potentiating effect of d(+)-mannose, orotic and hippuric acid on selective toxicity of mixture of thirteen substances of the circulatory system for various tumor cell lines in culture. Cancer Detect Prev 2000;24:485.

39. Kulcsár G. Apoptosis of tumor cells induced by substances of the circulatory system. Cancer Biother Radiopharm 1997;12:19.

40. Kulcsár G. Passive Antitumor Defense System: Hypothesis and Experimental Results. PhD Dissertation, University of Pécs, Hungary, 1998.

41. Kulcsár G. Theoretical and literary evidence for the existence of the passive antitumor defense system. Cancer Biother Radiopharm 1997;12:281.

42. Gorczyca W, Gong J, Ardelt B, et al. The cell cycle related differences in susceptibility of HL-60 cells to apoptosis induced by various antitumor agents. Cancer Res 1993;53:3186.

43. Oser BL. Hawk's Physiological Chemistry. New York: McGraw-Hill Book Co., 1965.

44. Maiani G, Azzini E, Ferro-Luzzi A. Vitamin C. Int J Vitam Nutr Res 1993;63:289.

45. Bartlett GR. Biology of free and combined adenine; distribution and metabolism. Transfusion 1977;17:339.

46. Bonjour JP. Biotin in man's nutrition and therapy-A review. Int J Vitam Nutr Res 1977;47:107.

47. Pitkänen E, Kanninen T. Determination of mannose and fructose in human plasma using deuterium labeling and gas chromatography/mass spectrometry. Biol Mass Spectrometry 1994;23:590.

48. Daniewska-Michalska D, Motyl T, Gellert R, et al. Efficiency of hemodialysis of pyrimidine compounds in patients with chronic renal failure. Nephron 1993;64: 193.

49. Pickert A, Bäuerle A, Liebich HM. Determination of hippuric acid and furanic acid in serum of dialysis patients and control persons by high-performance liquid chromatography. J Chromatography 1989;495:95.

50. White A, Handler P, Smith EL. Principles of Biochemistry. Tokyo: Kogakusha Co. Ltd., 1968:706.

51. Farkas E. Drug Treatment of Malignant Tumors. Medicina Budapest: Könyvkiadó, 1984.

52. Marks A, Ettenson D, Bjorn MJ, et al. Inhibition of hu- man tumor growth by intraperitoneal immunotoxins in nude mice. Cancer Res 1990;50:288.

53. Vermes I, Haanen C. Apoptosis and programmed cell death in health and disease. Adv Clin Chem 1994;31: 177.

54. Möller G, Möller E. Considerations of some current concepts in cancer research. J Natl Cancer Inst 1975; 55:755.

55. Fialkow PJ. Clonal origin of human tumors. Ann Rev Med 1979;30:135.

56. Cameron E, Pauling L. Supplemental ascorbate in the supportive treatment of cancer: Prolongation of survival times in terminal human cancer. Proc Natl Acad Sci USA 1976;73:3685.

57. Park CH, Amare M, Savin MA, Hoogstraten B. Growth suppression of human leukemic cells in vitro by Lascorbic acid. Cancer Res 1980;40:1062.

58. Lubec B, Hoeger H, Kremser K, et al. Decreased tumor incidence and increased survival by one year oral low dose arginine supplementation in the mouse. Life Sci 1996;58:2317.

59. Ulrich F. Inhibition by 2-deoxy-D-ribose of DNA synthesis and growth in Raji cells (42693). Proc Soc Exp Biol Med 1988;187:488.

60. Gonzalez F, Amos H. Effects of naturally occurring sugars on Ehrlich ascites tumor growth in mice. J Natl Cancer Inst 1977;58:1519.

61. Sidransky H, Verney E. Influence of orotic acid on liver tumorigenesis in rats ingesting ethionine, $\mathrm{N}$-2-fluorenylacetamide, and 3'-methyl-di-methylamino-azobenzene. J Natl Cancer Inst 1970;44:1201.

62. Demetrakopoulos GE, Brennan MF. Tumoricidal potential of nutritionalmanipulations. Cancer Res 1982;42 (suppl.):756s.

63. Krishnaswamy K, Prasad MP, Krishna TP, et al. A case study of nutrient intervention of oral precancerous lesions in India. Eur J Cancer B Oral Oncol 1995;31B:41.

64. Pawlek JM. Factors regulating growth and pigmentation of melanoma cells. J Invest Dermatol 1976;66:201.

65. Kulcsár G. Pharmaceutical compositions for prevention and treatment of cancerous disease and process for their preparation. Hungarian patent: Patent number: 213677 , Issuance: 06/08/98. 